\title{
Surgery in acute patellar dislocation-evaluation of the effect of injury mechanism and family occurrence on the outcome of treatment
}

\author{
H Mäenpää, M U K Lehto* \\ Department of Clinical Science, University of Tampere and *Department of Surgery, Division of Orthopaedics, \\ University Hospital of Tampere, Finland
}

\begin{abstract}
A retrospective study was made of 270 patients and 284 knees with acute patellar dislocation treated operatively. The mean follow up time was 4.1 years. Medical history revealed $21.1 \%$ of cases with previous dislocations and $15.6 \%$ of cases with family occurrence of patellar dislocation. The dislocation resulted from an athletic performance in $41.5 \%$ of cases. The sport events most often associated with patellar dislocation were soccer, gymnastics, and ice hockey. All cases were treated with reefing of medial capsule. Release of lateral patellar retinacula was performed in 243 cases. Two cases were treated primarily with the Elmslie-Roux-Trillat procedure. The subjective result of operative treatment was better and the redislocation rate was lower if the injury mechanism was traumatic rather than non-traumatic and if there was no history for family occurrence of patellar dislocation. (Br J Sports Med 1995; 29 : 239-241)
\end{abstract}

Keywords: Patellar dislocation; operative treatment; family history

Acute traumatic dislocation of patella is often diagnosed as a cause for acute haemarthrosis of the knee. ${ }^{1-3}$ It is an injury of young people, associated typically with athletic performances. ${ }^{45}$ Dislocation can be treated conservatively ${ }^{4-8}$ or operatively. ${ }^{9-11}$ Operative treatment should be considered when there are signs of anatomical variations that would predispose to recurrent dislocation, especially in patients with intraarticular fragments and in athletes. ${ }^{6} 712$ Predisposing factors include abnormal morphology of the patella, ${ }_{13}^{13}$ high riding patella, ${ }^{4}$ low lateral femoral condyle, ${ }^{15}$ lateral insertion of the patellar tendon, ${ }^{16}$ lax medial quadriceps retinaculum, ${ }^{17}$ and generalized familial joint laxity. ${ }^{18}$ Recurrent dislocation occurs with minor trauma, usually spontaneously in normal daily activities. Because of the development of the patellofemoral osteoarthritis in recurrent dislocation, primary dislocation should be treated adequately..$^{19} 20$

In the present study it was our aim to evaluate the results of surgical treatment of acute patellar dislocation in patients with traumatic and non-traumatic injury

Address for correspondence: Matti U K Lehto, Department of Surgery, Division of Orthopaedics, University Hospital of Tampere, PO Box 2000, SF-33251 Tampere, Finland mechanism with special reference to associated family occurrence.

\section{Methods}

From January 1982 to December 1989, 270 patients and 284 knees with acute lateral dislocation of the patella were treated operatively at the University Hospital of Tampere, Finland. There were 161 women and 109 men. The mean age in women was 23.5 (range 9-56) years and in men 22.6 (range 12-42) years. The left knee was involved in 142 cases and the right one in 142 .

There was a history of previous patellar dislocations in 60 cases. Treatment of these dislocations had been operative in 20 cases and conservative in 40 cases. There were four patients with previous meniscus tears.

The dislocation resulted from an athletic performance in 118 cases; most commonly soccer $(n=20)$, gymnastics $(n=16)$ and ice hockey $(n=15)$. In men dislocation occurred most often in soccer $(n=18)$ and in women in gymnastics $(n=15)$. The most common causes were flexion/inward rotation of the knee, or a direct blow or kick to the knee. In 70 cases the dislocation was present in the emergency room and in the remaining 214 the dislocation had been reduced in the site of injury. Aspiration of the knee joint was performed in 109 cases. The mean volume of haemarthrosis was $48 \mathrm{ml}$ (range 5-160).

The surgical procedure used in all cases was reefing of the medial capsule. Release of the lateral patellar retinaculum was performed in 243 cases. Two cases were treated primarily with a distal realignment (Elmslie-Roux-Trillat) procedure. Arthroscopy was performed before the surgical procedure in 40 cases.

Postoperatively 59 cases were immobilized by a plaster cast for 5 (range 3-8) weeks. In the rest of the cases $(n=225)$, the knee was mobilized immediately postoperatively in from $0-30^{\circ}$ flexion, for a mean period of 6 (range 2-6) weeks; thereafter a full range of motion was allowed.

The cases could be divided into two groups:

1. Traumatic group: no previous history of subluxations or dislocations. Traumatic dislocation mechanism (torsion, blow, kick). 
Table 1. Distribution of patellar dislocation between traumatic and non-traumatic cases

\begin{tabular}{|c|c|c|c|c|c|}
\hline \multirow[b]{2}{*}{ Group } & \multirow{2}{*}{$\begin{array}{l}\text { No of } \\
\text { cases }\end{array}$} & \multicolumn{2}{|c|}{ Sex } & \multicolumn{2}{|c|}{ Age (years) } \\
\hline & & $F$ & $M$ & $F$ & $M$ \\
\hline Traumatic & 177 & 102 & 75 & 24.5 & 23.3 \\
\hline Non-traumatic & 107 & 69 & 38 & 22.1 & 22.9 \\
\hline Total & 284 & 171 & 113 & 23.5 & 22.6 \\
\hline
\end{tabular}

2. Non-traumatic group: previous history of subluxations or dislocations. Non-traumatic dislocation mechanism (rotation of flexion-extension of the lower limb in normal daily activities).

Characteristics of the two groups are presented in Table 1.

This report is based on patient records and a questionnaire which was answered by 213 patients $(75.0 \%)$, five incompletely, and therefore the number of patients varies from 208 to 213 in the tables. The mean follow up time was 4.1 (range 2-9) years. A subjective assessment of the result of the treatment was carried out by questionnaire using the following criteria:

1. Excellent: no pain; no weakness of extensor mechanism; no instability of the patella.

2. Good: occasional pain; mild weakness of extensor mechanism; slight instability of the patella with occasional subluxations.

3. Fair: moderate pain; weakness of extensor mechanism; definite instability of the patella with subluxations.

4. Poor: severe pain; severe weakness of extensor mechanism; recurrent dislocation of the patella.

Statistical calculations were done by the Mann-Whitney $U$ test and by the $\chi^{2}$ test (applying Yates' correction for continuity), taking $P$ values of less than 0.05 as statistically significant.

\section{Results}

\section{General findings}

Preoperative examination usually showed effusion or subcutaneous oedema $(n=279)$, loss of movement $(n=257)$, and medial tenderness $(n=230)$. The aspirate was larger $(55 \mathrm{ml}$ versus $37 \mathrm{ml})$ when intraarticular damage was present.

A medial margin fracture of the patella was found in 79 cases and a loose intra-articular fragment in $34 ; 18$ fragments were from the lateral femoral condyle and 16 from the patella. Fragments were refixed in 13 cases and extracted in 17. In four cases the data were missing. Three medial meniscus, five medial collateral, and two anterior cruciate ligament tears were recorded. Following operation there were eight wound haematomas, nine superficial wound infections, and two cases of deep venous thrombosis.
Table 2. Subjective result of the operative treatment

\begin{tabular}{lccccc}
\hline & \multicolumn{4}{c}{ Subjective result } & \\
\cline { 2 - 5 } Group* & Excellent & Good & Fair & Poor & $\begin{array}{c}\text { Excellent } \\
\text { or good }\end{array}$ \\
\hline Traumatic & 24 & 72 & 29 & - & 77 \\
Non-traumatic & 13 & 39 & 29 & 5 & 60 \\
\hline
\end{tabular}

${ }^{*} n=211 ; \chi^{2}=11.26 ; P=0.01$

Table 3. Incidence of family history in patellar dislocation

\begin{tabular}{|c|c|c|c|}
\hline \multirow[b]{2}{*}{ Group* } & \multicolumn{2}{|c|}{ Family history } & \multirow[b]{2}{*}{$\%$ With history } \\
\hline & With & Without & \\
\hline Traumatic & 8 & 118 & 6 \\
\hline Non-traumatic & 25 & 60 & 29 \\
\hline
\end{tabular}

${ }^{*} n=211 ;$ corrected $\chi^{2}=19.13 ; P<0.0001$

Table 4. The subjective result of operative treatment in relation to family history of patellar dislocation*

\begin{tabular}{lccccc}
\hline & \multicolumn{4}{c}{ Subjective result } & \\
\cline { 2 - 5 } $\begin{array}{l}\text { Family } \\
\text { history }\end{array}$ & Excellent & Good & Fair & Poor & $\begin{array}{c}\text { Excellent } \\
\text { or good }\end{array}$ \\
\hline With & 2 & 15 & 13 & 3 & 52 \\
Without & 35 & 95 & 43 & 2 & 74 \\
\hline
\end{tabular}

${ }^{*} n=208 ; \chi^{2}=13.00 ; P=0.005$

\section{Questionnaire study}

The subjective result $(n=211)$ was excellent in 37 cases $(17.5 \%)$, good in $111(52.6 \%)$, fair in $58(27.5 \%)$, and poor in five $(2.4 \%)$ cases. In the traumatic group, $77 \%$ were excellent or good; none were poor. In the non-traumatic group $60 \%$ were excellent or good, $5.8 \%$ were poor (Table 2).

There was a family history of patellar dislocation in 33 cases $(n=211)$ (Table 3$)$. In those with a family history of dislocation the outcome was less satisfactory (Table 4). Of 212 patients, $37 \%$ lowered their level of sports activity following injury.

The type of sport was different in 61 cases $(30.3 \%)$ $(n=201)$. Of these $23(37.7 \%)$ were in the traumatic group and $38(62.3 \%)$ in the non-traumatic group.

Redislocation occurred in 37 cases (17.4\%) $(n=213)$ : three $(8.1 \%)$ in the traumatic group and 34 $(92 \%)$ in the non-traumatic group. Family history was also significant with 19 redislocations $(35.0 \%)$ if there was a family history and $17(11 \%)$ if not.

No significant difference was found between the two methods of postoperative treatment: immobilization or mobilization.

\section{Discussion}

There was a predominance of women in our study. This distribution has been reported previously. ${ }^{4} 78_{11} 12$ 21 Some investigators ${ }^{6}{ }^{10}$ have stated that patellar dislocation occurs more frequently in males than in females. In addition, Hughston ${ }^{4}$ and Hughston et al. ${ }^{5}$ reported 
that predominance of males correlates with higher athletic activity. In the present study, if only athletic injuries are included the sex ratio is similar to those studies. $^{5}$

The sports most often associated with acute patellar dislocation were soccer, gymnastics and ice hockey-all popular in Finland. Surprisingly few dislocations occurred in skiing $(n=3)$. Asikainen et al $^{22}$ reported that downhill skiing injuries in Finland are few, apparently because Finns are skilled and experienced skiers. A typical mechanism of knee injury in skiing (outward rotation, valgus force) differs from the injury mechanism of patellar dislocation.

There was a family history of patellar dislocation in $15.6 \%$. Previous studies ${ }^{19} 2324$ showed a $13-28 \%$ positive family history in patients with recurrent dislocations. In this study the occurrence was $29.4 \%$ if we include only cases in the non-traumatic group. In our traumatic group there was a positive family history in $6.3 \%$ of cases and in our non-traumic group $29.4 \%$. The difference was statistically significant $(P<0.0001)$. The subjective results were worse $(P=0.005)$ and occurrence of redislocations higher $(P<0.0001)$ with a positive family history.

Runow ${ }^{25}$ suggests that factors leading to dislocation may be external or internal, where trauma is - at least partly - an external factor, and general joint laxity with associated family history an internal factor. Recurrent dislocation of the patella has been considered to be a manifestation of generalized joint laxity. ${ }^{18}$ Recently, Borochowtiz et al. ${ }^{26}$ have suggested that autosomal dominant inheritance without generalized joint laxity may be a factor in familial recurrent dislocation of the patella.

The subjective result of the operative treatment (76.8\% excellent or good) was significantly better in the traumatic group $(P=0.01)$. Only three of the total of 37 redislocations occurred in this group $(P<0.0001)$. The recurrence rate of $2.4 \%$ in the traumatic group is low and in accordance with earlier reports, which have included only first time dislocations. ${ }^{11}{ }^{12} 2127$ Conversely, in the non-traumatic group the subjective results of operative treatment $(60.4 \%$ excellent or good) and recurrence rate $(38.6 \%)$ are unsatisfactory.

While there was no difference $(P=0.15)$ between the groups in present sports activity, the sport had been changed much more often in those with a family history of dislocation. We speculate that it may be that a patient in the non-traumatic group is forced to change to an easier sport, but is now happy in the new interest.

In this study the aim was not to study the clinical results obtained after surgical treatment of patellar dislocation, which has been reported in several studies. $^{6}{ }^{9-12} 192127$ This investigation concentrated on the importance of the injury mechanism and family occurrence in the outcome of surgical treatment of patellar dislocation. This justifies the use of a questionnaire. The results show that medial reefing and lateral release are adequate procedures in the primary dislocation of the patella with traumatic aetiology, but fail to treat cases with the predisposing factors of previous dislocations of the patella or positive family history.

\section{References}

1 Harilainen A et al. The significance of arthroscopy and examination under anaesthesia in the diagnosis of fresh injury hemarthrosis of the knee joint. Injury 1988; 19 : 21-4.

2 Sperner $G$ et al. Arthroscopy of traumatic hemarthrosis following sports injuries. A 5 year analysis. Aktuel Traumatol 1990; 20: 162-6.

3 Benedetto KP et al. Knee joint hemarthrosis-differential diagnostic considerations for planning an operation. Orthopade 1990; 19: 69-76.

4 Hughston JC. Subluxation of the patella. J Bone Joint Surg [Am] 1968; 50-A : 1003-26.

5 Hughston JC, Walsh WM, Puddy G. Patellar subluxation and dislocation. Saunders monographs in clinical orthopaedics. Philadelphia, USA: WB Saunders, 1984: 5.

6 Cash JD, Hughston JC. Treatment of acute patellar dislocation. Am J Sports Med 1990; 16: 244-9.

7 Cofield RH, Bryan RS. Acute dislocation of the patella. Results of conservative treatment. J Trauma 1977; 17: 526-31.

8 Larsen EL, Lauridsen F. Conservative treatment of patellar dislocation. Influence of evident factors on the tendency to redislocations and the therapeutic results. Clin Orthop 1982; 171: 131-6.

9 Boring $\mathrm{TH}, \mathrm{O}^{\prime}$ Donoghue $\mathrm{OH}$. Acute patellar dislocation. Results of immediate surgical repair. Clin Orthop 1978; 136: 182-5.

10 Scuderi $G$ et al. Lateral release and proximal realignment for patellar subluxation and dislocation. J Bone Joint Surg $[\mathrm{Am}] 1988$; 70-A: 856-61.

11 Vainionpää $\mathrm{S}$ et al. Acute dislocation of the patella. A prospective review of operative treatment. J Bone Joint Surg [Br] 1990; 72-B: 366-8.

12 Hawkins RS et al. Acute patellar dislocation. The natural history. Am J Sports Med 1986; 14: 117-20.

13 Wiberg G. Roentgenographic and anatomic studies of the femoropatellar joint with special reference to chondromalasia patellae. Acta Orthop Scand 1941; 12 : 319-410.

14 Baumgartl F. Anatomische und koinische Bedentung des Femoropatellargelenhus. Zentralbl Chir 1966; 91: 505-16.

15 Brattström H. Shape of the intercondylar groove normally and in recurrent dislocation of patella. Acta Orthop Scand 1964; (Suppl. 68).

16 Smillie IS. Injuries of the knee joint. Baltimore: Williams and Wilkins, 1968.

17 Coleman HM. Recurrent osteochrondral fracture of the patella. J Bone Joint Surg [Br] 1948; 30-B : 153-7.

18 Carter C, Sweetnam R. Familial joint laxity and recurrent dislocation of the patella. J Bone Joint Surg $[\mathrm{Br}] 1958 ;$ 40-B : 664-7.

19 Crosby EB, Insall J. Recurrent dislocation of the patella. Relation of treatment of osteoarthritis. J Bone Joint Surg $[A m] 1976 ; \mathbf{5 8 - A}$ : 9-13.

20 Iwano $\mathrm{T}$ et al. Roentgenographic and clinical findings of patellofemoral osteoarthritis. Clin Orthop 1990; 252 : 190-7.

21 Harilainen A, Myllynen P. Operative treatment in acute patellar dislocation: radiological predispositing factors, diagnosis and results. Am J Knee Surg 1988; 1: 178-85.

22 Asikainen $\mathrm{P}$ et al. Downhill skiing injuries and their cost at a Finnish skiing area. Scand J Med Sci Sports 1991; 1 : 228-31.

23 Carter C, Sweetnam R. Recurrent dislocation of the patella and of the shoulder. J Bone Joint Surg $[\mathrm{Br}] 1960 ;$ 42-B: 721-7.

24 Hampson WGJ, Hill P. Late results of transfer of the tibial tubercle for recurrent dislocation of the patella. J Bone Joint Surg $[\mathrm{Br}] 1975$; 57-B: 209-13.

25 Runow A. The dislocating patella. Etiology and prognosis in relation to generalized joint laxity and anatomy of the patellar articulation. Acta Orthop Scand 1983; (Suppl. 201).

26 Borochowitz ZVI et al. Familial recurrent dislocation of patella with autosomal dominant mode of inheritance. Clin Genet 1988; 33: 1-4.

27 Jensen CM, Roosen JU. Acute traumatic dislocations of the patella. J Trauma $1985 ; 25$ : 160-2. 